\title{
Endovascular treatment of thoracoabdominal aortic aneurysm: a case report
}

\author{
Arash Mohammadi Tofigh ${ }^{1 *}$, Massoud Ghasemi², Babak Heidari Aghdam², Mersedeh Karvandi ${ }^{3}$, Afsoon Kaboli²
}

\begin{abstract}
Introduction: Thoracoabdominal aortic aneurysms usually present in elderly patients with serious renal, pulmonary, cerebral, or cardiac comorbidities that pose a great challenge to the attending surgeon. Endovascular techniques for the treatment of thoracoabdominal aneurysms are not yet widely used due to limitations associated with them, such as spinal and visceral ischemia.
\end{abstract}

Case presentation: An 87-year-old Caucasian man with a symptomatic Crawford type I thoracoabdominal aortic aneurysm was treated successfully with a long tube stent graft using endovascular techniques and without any complication in follow-up examinations. The stent was placed distal to the left subclavian artery, and proximal to the celiac axis.

Conclusion: The use of endovascular stents for long segment thoracoabdominal aortic aneurysms needs to undergo clinical investigation to determine whether this procedure decreases morbidity and mortality rates.

\section{Introduction}

Advancements in diagnostic techniques have made the detection of thoracoabdominal aortic aneurysm feasible, with most centers reporting an increase of $5 \%$ in the detection of suprarenal aneurysms. Thoracoabdominal aortic aneurysms are usually identified in elderly patients with serious renal, pulmonary, cerebral, or cardiac comorbidities that pose a great challenge to the attending surgeon [1]. Surgery necessitates a thoracoabdominal incision that will approach the aneurysm through the retroperitoneum and mobilize the visceral organs medially. In some cases, the surgeon utilizes cardiopulmonary bypass to perfuse the distal vessels, hoping to decrease the incidence of paraplegia [2].

The advent of endovascular aortic prosthesis provides patients with alternative therapy which hopes to decrease the morbidity and mortality of surgery [3]. Endovascular techniques are well described for abdominal and thoracic aortic aneurysms. These techniques are quite new as applied to thoracoabdominal aneurysms, however, due to serious adverse events such as spinal and visceral ischemia following the procedure [4]. We describe in this case report a patient with an

\footnotetext{
*Correspondence: Arash_mtofigh@yahoo.com
'Imam Hossein Medical Center, Shahid Beheshti University of Medical

* Correspondence: Arash_mtofigh@yahoo.com
'Imam Hossein Medical Center, Shahid Beheshti University of Medical Sciences, Tehran, Iran
}

(c) 2010 Mohammadi Tofigh et al; licensee BioMed Central Ltd. This is an Open Access article distributed under the terms of the

extensive Crawford type I thoracoabdominal aneurysm treated with the placement of a stent graft in the thoracic aorta using endovascular techniques.

\section{Case presentation}

An 87-year-old Caucasian man presented to our institution with chest and epigastric pain radiating to his back. Computed tomographic scans were performed urgently, and these showed a large Crawford type I thoracoabdominal aortic aneurysm (Figure 1). The aneurysm measured $17 \mathrm{~cm}$ in length and was $5 \mathrm{~cm}$ to $6 \mathrm{~cm}$ distal from the left subclavian artery and $2 \mathrm{~cm}$ to $3 \mathrm{~cm}$ proximal to the celiac axis. The maximum anteroposterior diameter of the aneurysm was $13 \mathrm{~cm}$ above the diaphragm. The aorta between the celiac axis and the renal arteries was of normal size. Another aneurysm measuring $6 \mathrm{~cm}$ in length and $4 \mathrm{~cm}$ in diameter with no extension to the iliac arteries was detected distal to the renal arteries.

Our patient was not in a fit condition to undergo open surgery, so endovascular surgery was the preferred option. The diameters of the proximal and distal necks of the aneurysm were $3.2 \mathrm{~cm}$ and $3.4 \mathrm{~cm}$, and a large mural thrombosis was present along all its length. We decided to treat our patient with a single tube stent graft. Although a long segment of the aorta would be 


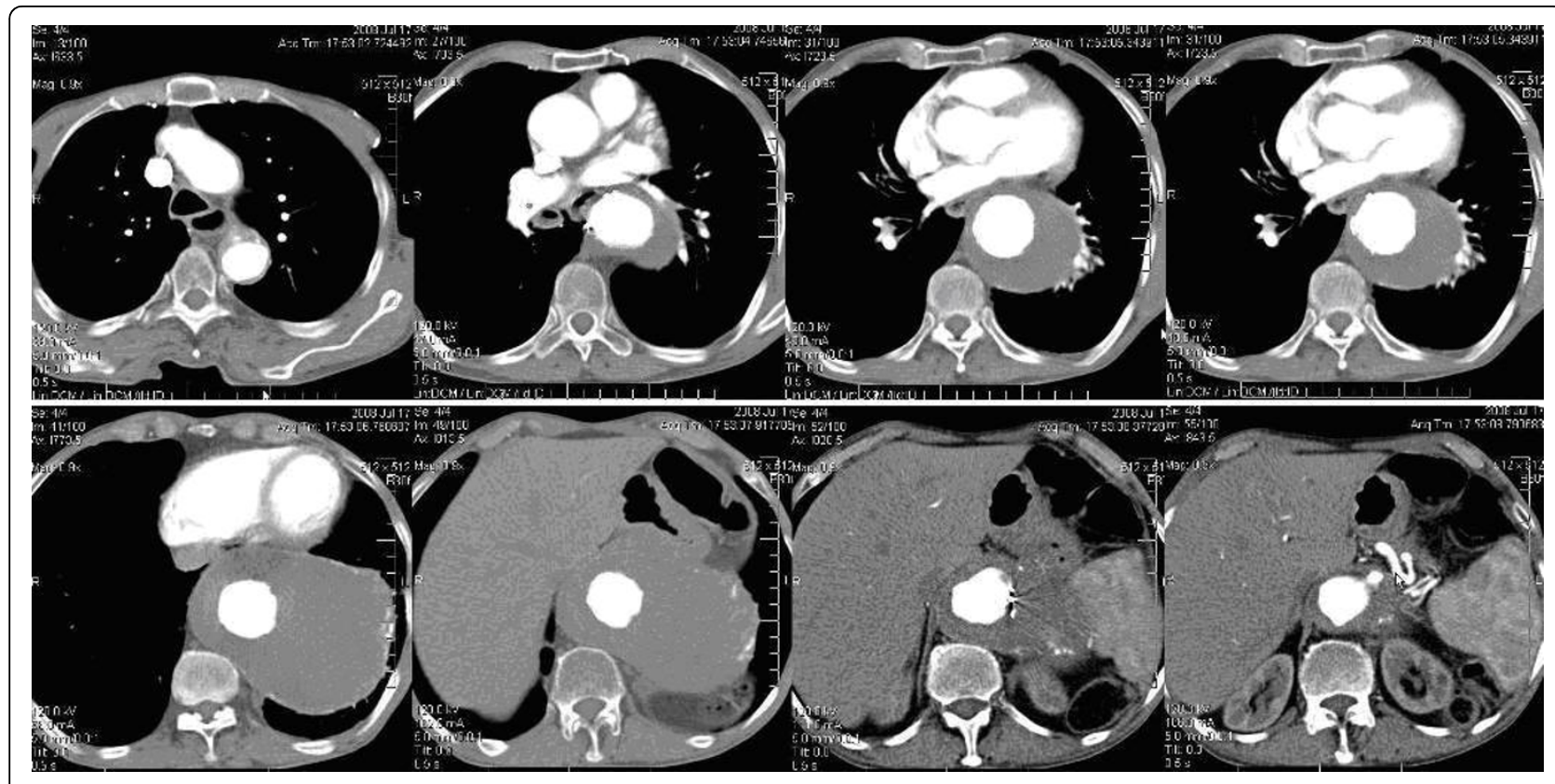

Figure 1 Computed tomography scan showing the patient's Crawford Type I thoracoabdominal aneurysm

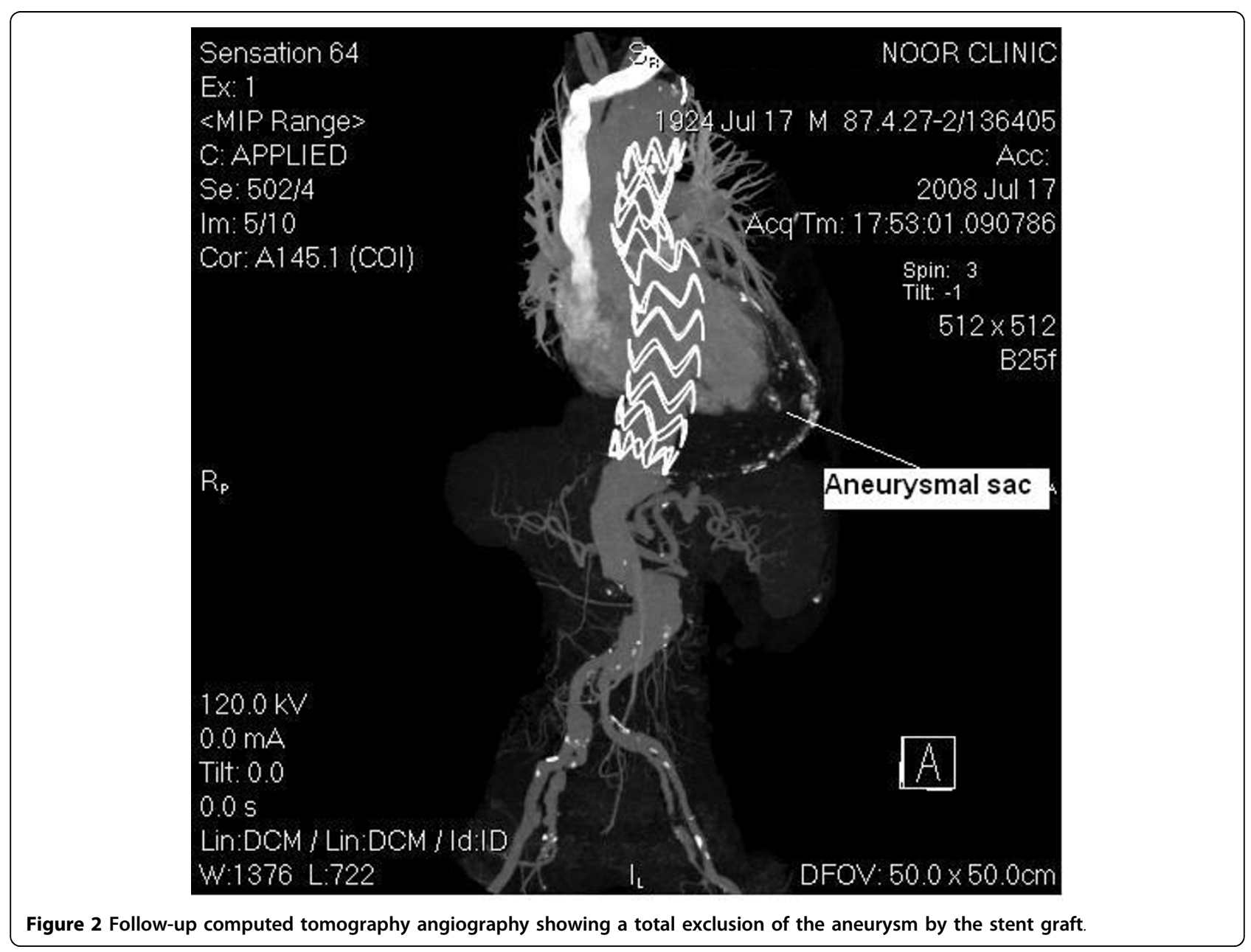


covered during the procedure, we considered that there was a low chance of spinal ischemia, as the mural thrombosis had plugged all of his intercostal and lumbar arteries. Cerebrospinal fluid drainage was considered as a protective move for spinal circulation during the procedure.

Under general anesthesia, our patient's right femoral artery was dissected and controlled. An endovascular stent graft (VALIANT TF 4242C200X, Medtronic) was deployed distal to the left subclavian artery, thus covering the aneurysm. The stent graft was $21 \mathrm{~cm}$ in length and was placed just above his celiac axis. We controlled the proximal end deployment by real-time transesophageal echocardiography, and the distal end deployment under angiography. Follow-up transesophageal echocardiography, computed tomography and angiography showed a complete exclusion of the thoracoabdominal aneurysm (Figure 2). Correction of the abdominal aortic aneurysm was programmed for later. The patient was discharged three days after the procedure and showed no complications during the succeeding nine months.

\section{Discussion}

The surgical treatment of thoracoabdominal aneurysms poses a major challenge to the vascular surgeon, especially because patients are usually elderly and have serious comorbidities. The development of endovascular prostheses has greatly improved the treatment of patients with aneurysm or dissection in the thoracic and abdominal aorta [4-6]. This is a major achievement in the therapy of these types of aneurysms, but it necessitates precise diagnostic investigations to determine the proximal and distal necks of the aneurysm, the vessels involved in the aneurysm, and the location of tears in aortic dissection. One of the major challenges is the risk of paraplegia in patients who undergo surgical treatment of these aneurysms. Short cross-clamp time, distal perfusion, hypothermia, cerebrospinal fluid drainage and the use of steroids are some of the strategies aimed at decreasing the risks of surgery [7].

The use of endovascular stents could potentially decrease the risk of paraplegia and serious morbidities associated with the surgical approach. Using a long tube stent graft to exclude the aneurysm is a new approach to treat thoracoabdominal aortic aneurysms. However, serious complications like visceral and spinal ischemia should still be considered before surgery. Graft distortion will be considered as a potential risk in longer stent grafts and controlling the whole procedure using realtime angiography and transesophageal echocardiography is very important to avoid this complication [8]. Chuter et al. [9] developed a multi-branched stent graft for the treatment of thoracoabdominal aneurysm that would decrease the risk of visceral ischemia. This device, however, is still in the experimental phase.

\section{Conclusion}

The use of endovascular stents for long segment thoracoabdominal aortic aneurysms will have to undergo clinical investigation to determine whether the stents decrease the morbidity or mortality rates associated with the condition. Although the patient described in this case report is doing well at nine months, a longer follow-up time is needed to further identify the beneficial effects of this new approach to a complex problem.

\section{Patient's perspective}

Following the intervention our patient said that he had not believed that his condition would be treated so easily and he had expected a serious open surgery.

\section{Consent}

Written informed consent was obtained from the patient for publication of this case report and any accompanying images. A copy of the written consent is available for review by the Editor-in-Chief of this journal.

\section{Acknowledgements}

We thank the staff of the catheterization laboratory of the Imam Khomeini Hospital for their valuable assistance to the authors.

\section{Author details}

${ }^{1}$ Imam Hossein Medical Center, Shahid Beheshti University of Medical Sciences, Tehran, Iran. ${ }^{2}$ Research Center of Endovascular Intervention, Tehran, Iran. ${ }^{3}$ Taleghani Hospital, Shahid Beheshti University of Medical Sciences, Tehran, Iran.

\section{Authors' contributions}

AMT served as the vascular surgeon to the patient described in this case report. MG, AK and BHA were the interventionists, while MK was the echocardiologist. All authors read and approved the final manuscript.

\section{Competing interests}

The authors declare that they have no competing interests.

\section{Received: 29 October 2009}

Accepted: 2 February 2010 Published: 2 February 2010

\section{References}

1. Okita Y, Ando M, Minatoya K, Tagusari O, Kitamura S, Nakajima N, Takamoto S: Early and long-term results of surgery for aneurysms of the thoracic aorta in septuagenarians and octogenarians. Eur J Cardiothorac Surg 1999, 16:317-323.

2. Svensson LG, Crawford E, Hess KR, Coselli JS, Safi HJ: Experience with 1509 patients undergoing thorocoabdominal operations. J Vasc Surg 1993, 17:357-370.

3. Parodi JC: Endovascular repair of abdominal aortic aneurysms and other arterial lesions. J Vasc Surg 1995, 21:549-557.

4. Dake MD, Kato N, Michell RS: Endovascular stent graft placement for the treatment of acute aortic dissection. N Engl J Med 1999, 340(20):1546-1552

5. Nienaber CA, Fattori R, Lund G, Dieckmann C, Wolf W, von Kodolitsch Y, Nicolas $V$, Pierangeli A: Non-surgical reconstruction of thoracic aortic dissection by stent graft placement. N Engl J Med 1999 340(20):1539-1545 
6. Palma JH, Almeida DR, Carvalho AC, Andrade JCS, Buffolo E: Surgical treatment of acute type $B$ aortic dissection using an endoprosthesis (elephant trunk). Ann Thorac Surg 1997, 63:1081-1084.

7. Griepp RB, Ergin MA, Galla JD, Lansman S, Khan N, Quintana C McCollough J, Bodian C: Looking for the artery of Adamkiewicz: a quest to minimize paraplegia after operations for aneurysms of the descending thoracic and thoracoabdominal aorta. J Thorac Cardiovasc Surg 1996, 112:1202-1215.

8. Hodgson R, McWilliams RG, Simpson A, Gould DA, Brennan JA, GillingSmith GL, Harris PL: Migration versus apparent migration: importance of errors due to positioning variation in plain radiographic follow-up of aortic stent grafts. J Endovasc Ther 2003, 10(5):902-910.

9. Chuter TA, Gordon RL, Reilly LM, Pak LK, Messina LM: Multi-branched stent graft for type 3 thoracoabdominal aortic aneurysm. J Vasc Interv Radiol 2001, 12(3):391-392.

doi:10.1186/1752-1947-4-37

Cite this article as: Mohammadi Tofigh et al:: Endovascular treatment of thoracoabdominal aortic aneurysm: a case report. Journal of Medical Case Reports 2010 4:37.

\section{Submit your next manuscript to BioMed Central} and take full advantage of:

- Convenient online submission

- Thorough peer review

- No space constraints or color figure charges

- Immediate publication on acceptance

- Inclusion in PubMed, CAS, Scopus and Google Scholar

- Research which is freely available for redistribution

Submit your manuscript at www.biomedcentral.com/submit 